\title{
Mechanical Behavior of Surgical Meshes for Abdominal Wall Repair: In vivo versus Biaxial Characterization
}

\author{
R. Simón-Allué ${ }^{\mathrm{a}, *}$, A. Ortillés ${ }^{\mathrm{a}}$, B. Calvo ${ }^{\mathrm{a}, \mathrm{b}}$ \\ ${ }^{a}$ AMB. Aragon Institute of Engineering Research (I3A), University of Zaragoza, Spain. \\ ${ }^{\mathrm{b}}$ Centro de Investigación Biomédica en Red en Bioingeniería, Biomateriales y Nanomedicina \\ (CIBER-BBN), Spain.
}

\begin{abstract}
Despite the widespread use of synthetic meshes in the surgical treatment of the hernia pathology, the election criteria of a suitable mesh for specific patient continues to be uncertain. Thus, in this work, we propose a methodology to determine in advance potential disadvantages on the use of certain meshes based on the patient-specific abdominal geometry and the mechanical features of the certain meshes.

To that purpose, we have first characterized the mechanical behavior of four synthetic meshes through biaxial tests. Secondly, two of these meshes were implanted in several New Zealand rabbits with a total defect previously created on the center of the abdominal wall. After the surgical procedure, specimen were subjected to in vivo pneumoperitoneum tests to determine the immediate post-surgical response of those meshes after implanted in a healthy specimen. Experimental performance was recorded by a stereo rig with the aim of obtaining quantitative information about the pressuredisplacement relation of the abdominal wall. Finally, following the procedure presented in prior works (Simón-Allué et al., 2015; Simón-Allué et al., 2017), a finite element model was reconstructed from the experimental measurements and tests were computationally reproduced for the healthy and herniated cases. Simulations were compared and validated with the in vivo behavior and results were given along the abdominal wall in terms of displacements, stresses and strain.

Mechanical characterization of the meshes revealed Surgipro ${ }^{T M}$ as the most rigid implant and Neomesh SuperSoft ${ }^{\circledR}$ as the softer, while other two meshes (Neomesh Soft ${ }^{\circledR}$, Neopore ${ }^{\circledR}$ ) remained in between. These two meshes were employed in the experimental study and resulted in similar effect in the abdominal wall cavity and both were close to the healthy case. Simulations confirmed this result while showed potential objections in the case of the other two meshes, due to high values in stresses or elongation that may led to discomfort in real tissue. The use of this methodology on human surgery may provide the surgeons with reliable and useful information to avoid certain meshes on specific-patient treatment.
\end{abstract}

Key words: Hernia repair, polypropylene prostheses, Biomechanical response, Mesh repair, In-vivo studies, Biaxial test. 


\section{Introduction}

Since the introduction of Lichtenstein's tension-free mesh procedure (Lichtenstein and Shulman, 1986; Amid et al., 1995; Sakorafas et al., 2001), the classic suture techniques have gradually given way to the use of a biomaterial for the surgical repair of an abdominal wall hernia, which is today practically standard practice (Rutkow, 2003; Kulacoglu, 2011). However, despite the widespread use of the surgical meshes, there is not a guide or extended acceptance about which protheses is the ideal for each hernia case or patient typology. Surgeons are often forced to choose a mesh mostly based on their experience and knowledge.

Furthermore, variations between specimens should be also considered since abdominal wall may change from one individual to another. Factors like age, gender, physical condition or medical background may affect to the mechanical behavior of the wall in a way impossible to predict. Thus, to obtain reliable mechanical data about a particular abdominal hernia case, that leads to the most suitable implant choice, the patient-specific treatment seems indispensable.

Based on this point, surgeons have started to demand new techniques to determinate in advance how the implant-tissue union is going to perform on a specific patient (Gefen, 2012). Even though these techniques were not able to exactly reproduce all biological processes present in the soft tissue after an abdominal procedure, the goal is to quantify and compare the effect provoked by different surgical meshes right after the surgical procedure. For this purpose, computational methods remain as the key tool to provide surgeons with relevant information of the implant/tissue junction performance before the surgical procedure was carried out.

Attending to the mechanics of the hernia treatment, it is well known that mechanical properties of the surgical mesh need to approximate the mechanical properties of the abdominal wall (Conze and Klinge, 1999; Hernández et al., 2011). If the implant behaves much more rigid than the original soft tissue, it gives rise to tensile stresses that may tear the tissue surrounding, provoking pain and discomfort in the patient and increasing the risk of tissue damage (Paajanen and Hemunen, 2004). On the other hand, if the implant behaves much softer than the muscles replaced, it may lead to an hernia recurrence or the presence of "bulging" of the prothesis due to its lack of strength (Schoenmaeckers et al., 2010; Deerenberg et al., 2016).

Thus, in this article we propose a methodology to computationally predict and evaluate the mechanical performance of four synthetic meshes when they are inserted in a specific abdominal wall model. To that purpose, we first evaluate the in vitro mechanical response of the surgical meshes through biaxial tests and applied them to a patient-specific FE model to evaluate its performance in an abdominal wall. This FE model geometry was reconstructed from a real abdominal cavity following the methodology detailed in (Simón-Allué et al., 2017). Computational simulations were validated through in vivo tests for three of the four implants. The work developed in the presented article has been subdivided into three blocks, matching the Material

\footnotetext{
* Corresponding author. Mechanical Department. c/ María de Luna s/n 50018. Zaragoza. Spain. Email address: rsimon@unizar.es, Tel.: +34 876555187
} 
and Methods distribution (see Fig. 1): Section 2.1, with regard to the surgical meshes and the in vitro mechanical characterization through biaxial tests; Section 2.2, related to the in vivo experimental testing performed on herniated animal model, from procedure to geometry reconstruction; and Section 2.3, where the FE model was reconstructed and numerical simulations were carried out.

\section{Materials and methods}

\subsection{In vitro experimental testing of surgical meshes}

\subsubsection{Surgical meshes}

Four surgical meshes were used for this study, all of them non-absorbable, biocompatible and polypropylene monofile meshes: Neomesh Soft ${ }^{\circledR}$ (NM, DIMA S.L., $40 \mathrm{~g} / \mathrm{m}^{2}$ ), Neopore ${ }^{\circledR}$ (NP, DIMA S.L., $32.4 \mathrm{~g} / \mathrm{m}^{2}$ ), Neomesh SuperSoft ${ }^{\circledR}$ (SS, DIMA S.L., $18.10 \mathrm{~g} / \mathrm{m}^{2}$ ) and Surgipro ${ }^{\text {TM }}$ (SUR, Covidien, 84g/m2). All meshes are designed for abdominal and inguinal hernia repair as well as tissue reinforcement. Two directions, Direction 1 and 2 (see Fig. 2), were identified in the meshes in order to assess possible anisotropy.

\subsubsection{Experimental testing}

Mechanical tests were carried out on the implants: Neomesh Soft ${ }^{\circledR}$, Neopore ${ }^{\circledR}$ and Neomesh Supersoft $^{\circledR}$ (DIMA meshes). Mechanical data from Surgipro $^{T M}$ was obtained from a prior work (Cordero et al., 2015).

Six $35 \times 35[\mathrm{~mm}]$ strips were cut from each mesh and subjected to biaxial tests using a Instron BioPuls $^{T M}$ low-force planar-biaxial Testing System, with four independently cells with $10 \mathbf{N}$ or $50 \mathrm{~N}$ full scale load cell and a sensibility of $0.25 \%$. For all samples, Direction 1 defined on the meshes was aligned with the A axis of the machine (see Fig. 2). Custom-made clamps (grips) equipped with sandpaper at the clamping faces were used to grip the samples to the biaxial machine (see Fig. 3), keeping a distance between clamps of about $30 \mathrm{~mm}$. Each specimen was then preloaded $0.1 \mathrm{~N}$ along both axes in order to obtain a perfectly planar shape and define the zero load level. All samples were subjected to ten loading and unloading cycles were acquired for each protocol, where the first nine cycles ensured that the specimen was preconditioned and the tenth was used for subsequent analysis. For each sample, five different ratios TA:TB in A and B directions were tested (see Table 2), following protocols similar to those previously described by (Sacks, 2000) for biaxial mechanical evaluation. All tests were carried out in displacement control modality. In the case of SUR, since data was taken from literature, only three ratios were shown. 
To compare the mechanical response of the four meshes, force per unit width (Equivalent Piola Stress, EPS) was obtained using the expression $E P S=\frac{\text { Force }[N]}{\text { Width }[\mathrm{mm}]}$, where Force $[\mathrm{N}]$ is the load acquired during the test.

To fit the experimental results obtained, a strain energy function (SEF) which reproduces isotropic and anisotropic responses was considered:

$$
\bar{\Psi}=\frac{k_{1}}{2 k_{2}}\left[\exp \left(k_{2}(1-\rho)\left(\bar{I}_{1}-3\right)^{2}+k_{2} \rho\left(\bar{I}_{4}-1\right)^{2}\right)-1\right]
$$

This equation corresponds to a exponential strain energy function similar to that introduced by Holzapfel (2000) and Gasser et al. (2006). This SEF is dependent on two main material parameters $k_{1}$ and $k_{2}$, and a third one $\rho$ that controls the contribution of each term in the equation. The term that includes $\bar{I}_{1}$ is associated to the isotropic response of the material, while $\bar{I}_{4}$ concerns the anisotropic response. This anisotropy grade is determined by the insertion on a preferential direction aligned with Direction 2, according to the specific directions established on the surgical meshes (see Fig. 2).

The isotropic or anisotropic character of the mesh is conditioned by the parameter $\rho$, which is related to the fiber dispersion. When $\rho=0$ fibers are randomly distributed, so the material can be considered isotropic. On the contrary, when $\rho=1$ fibers are totally aligned in the Direction 2, and therefore the response of the material becomes fully anisotropic. When $\rho$ takes a value between those limits, both contributions (isotropic and anisotropic) have influence and the parameter $\rho=0$ works as a regulator of each one.

Material parameters and the coefficient $\rho$ were fitted by an iterative process minimizing the error committed between experimental and analytical curves. In the approach followed in this work, experimental curves were first averaged and then fit once using the Levenberg-Marquardt minimization algorithm (Marquardt, 1963). This algorithm is based upon minimization of an objective function, which for the case of biaxial tests takes the form of

$$
\chi^{2}=\sum_{i=1}^{n}\left[\left(E P S^{\exp }-E P S^{\text {num }}\right)_{i 1}^{2}+\left(E P S^{\exp }-E P S^{\text {num }}\right)_{i 2}^{2}\right]
$$

where EPS $S^{\exp }$ and $E P S^{\text {num }}$ represent the experimental (measured) and numerical values of EPS respectively. This equation is evaluated in each data point $(i)$ up to the total number of data points $(n)$. The subscripts 1 and 2 make reference to Directions 1 and 2 of the surgical mesh, respectively.

The quality of data fitting was assessed by calculating the coefficient of determination $R^{2}$ (Steel and Torrie, 1960), defined as 


$$
R^{2}=1-\frac{S S_{r e s}}{S S_{t o t}}=1-\frac{\sum_{i=1}^{n}\left[\left(E P S^{\text {num }}-E P S^{\exp }\right)_{i 1}^{2}+\left(E P S^{\text {num }}-E P S^{\exp }\right)_{i 2}^{2}\right]}{\sum_{i=1}^{n}\left[\left(E P S^{\exp }-\mu\right)_{i 1}^{2}+\left(E P S^{\exp }-\mu\right)_{i 2}^{2}\right]}
$$

In this equation, $S S_{\text {res }}$ is the residual sum of squares and $S S_{\text {tot }}$ the total sum of squares, both defined as indicated in the second part of the equation. Lately, $\mu$ is the mean stress define as $\mu=\frac{1}{n} \sum_{i=1}^{n}[E P S]_{i}$. The coefficient $R^{2}$ is an indicative of the goodness of the fitting, being 1.0 the solution that fits the data exactly.

\subsection{In vivo experimental testing on animal model}

The mechanical performance of two of the described surgical meshes was also analysed under in vivo conditions. To that purpose, experiments were carried out in an animal model. Thus, nine adult male New Zealand white rabbits obtained from the Animal Experimentation Service of the Research Support Services of the University of Zaragoza were used. Their weight ranged from 3.7 to $4.2 \mathrm{~kg}$. The animals were housed singly, and were watered and fed a standard chow diet ad libitum (Finished feed n. 511 ${ }^{\circledR}$; Food Corporation Guissona S.A., Lleida, Spain). All animals were healthy and free of clinically observable systemic diseases. All procedures were carried out under Project Licence PI 01/11 approved by the in-house Ethics Committee for Animal Experiments of the University of Zaragoza. The care and use of animals were performed accordingly with the Spanish Policy for Animal Protection RD53/2013, which meets the European Union Directive 2010/63 on the protection of animals used for experimental and other scientific purposes.

\subsubsection{Surgical procedure}

Experiments were divided into two groups: the group A (control) was compounded by five healthy specimens and the group B by four animals with an hernia defect repaired by a mesh. Two specimen were repaired with the Neopore Mesh ${ }^{\circledR}$ (NP) and the other two with Neomesh Soft ${ }^{\circledR}(\mathrm{NM})$.

Animals were intramuscularly anaesthetized with a mixture of medetomidine $(0.5 \mathrm{mg} / \mathrm{kg}$, Medeson; Uranovet, Barcelona, Spain), ketamine $\left(25 \mathrm{mg} / \mathrm{kg}\right.$, Imalgene $1000^{\circledR}$; Merial Laboratorios S.A., Barcelona, Spain) and buprenorphine $\left(0.05 \mathrm{mg} / \mathrm{kg}\right.$, Buprex ${ }^{\circledR}$; Fort Dodge Veterinaria S.A., Girona, Spain). Using a sterile surgical technique, an abdominal wall defect was created through a 7-cm midline incision beginning $2 \mathrm{~cm}$ below the xiphoid process. A $5 \mathrm{x} 7-\mathrm{cm}$ portion was excised of the anterior abdominal wall comprising the aponeurotic, muscular and peritoneal planes (see Fig. 4 (a)). The corresponding mesh was attached to the tissue defect by a continuous suture with 4/0 non-absorbable monofilament polypropylene (Premilene ${ }^{\circledR}$, B-Braun Vet-Care S.A., Barcelona, Spain) interrupted in the implant angles. In the case of anisotropy, the stiffest direction of the mesh was located aligned to the craneo caudal axis. The underside 
of the implants was placed in direct contact with the visceral peritoneum, whereas the upper side was in contact with the subcutaneous tissue. The subcutaneous tissue was then closed over the implants by a continuous suture and the skin by an intradermal suture, both with 4/0 absorbable monofilament glyconate (Monosyn ${ }^{\circledR}$, B-Braun Vet-Care S.A., Barcelona, Spain). Once the wound was closed, the visible scar was a $100-\mathrm{mm}$ incision along the linea alba direction (see Fig. 4).

Immediately after the surgical procedure, to minimize pain and avoid infections, intramuscular buprenorphine $\left(0,05 \mathrm{mg} / \mathrm{kg}\right.$ twice a day, Buprex ${ }^{\circledR}$; Fort Dodge Veterinaria S.A., Girona, Spain) and enrofloxacine $\left(10 \mathrm{mg} / \mathrm{kg}\right.$ twice a day, Alsir $5^{\circledR}$; Esteve Veterinaria S.A., Barcelona, Spain), and subcutaneous meloxicam $\left(0,2 \mathrm{mg} / \mathrm{kg}\right.$ once a day, Loxicom ${ }^{\circledR}$; Laboratorios Karizoo S.A., Barcelona, Spain) were administered in all animals for a week. Throughout the study, the animals were visually inspected for signs of seroma formation, wound infection and/or areas of mesh incompatibility.

After 15 days of the surgical procedure and immediately after the pneumoperitoneum tests, each animal was humanely euthanized with an overdose of intravenous sodium pentobarbital $\left(150 \mathrm{mg} / \mathrm{kg}\right.$, Dolethal ${ }^{\circledR}$; Vétoquinol E.V.S.A., Madrid, Spain).

\subsubsection{Experimental testing}

Using the protocol previously described in Simón-Allué et al. (2015), several pneumoperitoneum tests were performed on each animal, increasing the inner pressure from 0 to $12 \mathrm{mmHg}$. Specimens were cropped from front to rear legs and the abdominal surface was spotted with black dots (see Fig. 4 (c)). Then, the intraabdominal pressure was increased from $0 \mathrm{mmHg}$ to 12 $\mathrm{mmHg}$ while tests were recorded by a stereo rig necessary to the tracking of the points. Tests were repeated for four times, reaching zero state after each pneumoperitoneum, and first one was excluded from the study due to the preconditioning. During the experiment, animals were kept alive but completely anesthetized.

\subsection{Patient-specific reconstruction and FE model}

Frames for each level of pressure were extracted from the video recorded and post processed with the software PhotoModeler (2013). Based on the 3D measurements obtained after the postprocessing, three finite element models were reconstructed: one for the Neomesh Soft ${ }^{\circledR}$ protheses, one for the Neopore ${ }^{\circledR}$ protheses and a last one for the healthy case. An accurate description of the FE model recreation was previously detailed in Simón-Allué et al. (2017).

Spacial coordinates measured on the experimental tests were used to reproduce the initial numerical geometry of the external abdominal cavity. To do so, the 3D modelling software Rhinoceros was used to interpolate a surface through the fiducial points (black dots in 4) and Abaqus $C A E$ was used to reconstruct the 
finite element mesh along the geometry. A constant thickness of $3 \mathrm{~mm}$ (and 3 elements) was considered again for the abdominal surface. On the contrary, the mesh was simulated by a surface of $1 \mathrm{~mm}$ (and 1 element) of thickness. To simulate the continuous suture that joins the implant and the subcutaneous tissue, nodes of the mesh perimeter where merged to the surrounding tissue, so that no slipping was allowed between mesh and tissue. Boundary conditions reproducing the pneumoperitoneum tests were applied by clamping sides and back of the model.

In order to determine the effect of each mesh on the abdomen response, the four prothesis described in Section 2.1.1 were simulated on the same FE model. To do so, the NM was chosen as a model. Once the FE model was reconstructed, material properties were assigned with respect to the particular tissue: prosthesis properties were obtained from the biaxial tests and abdominal properties following the material distribution obtained by inverse analysis in SimónAllué et al. (2017). As a result, five FE models were analysed: one assuming only abdominal tissue simulating the behavior of the healthy specimen, and four models simulating the response on the abdomen after being repaired with each synthetic mesh.

Healthy abdominal tissue was modelled through the use of the Veronda-Westman model (Veronda and Westmann, 1970). It is defined by an exponential strain energy function (SEF, given in Equation 4), widely applied to soft tissues (Kauer et al., 2002; Oberai et al., 2009; Goenezen et al., 2011), corresponding to an incompressible, isotropic and nonlinear elastic model. This model is dependent on two parameters, $\mu$ and $\gamma$, whose spatial variation may provide different mechanical response regarding the tissue zones. Its optimal parameter distribution, able to reproduce the pneumoperitoneum tests conducted on the animal model, was obtained by inverse analysis in Simón-Allué et al. (2017), and it was used in the present FE model to model the mechanical behavior of abdominal tissue (see Fig. 5). In Equation 4, the volumetric part can be defined as $\Psi_{\text {vol }}=\frac{1}{D}(J-1)^{2}$, where $D$ is the compressibility coefficient and $J$ the Jacobian of the deformation gradient $\left(F=\frac{\partial x}{\partial \mathbf{x}}\right)$.

$$
\Psi=\Psi_{\mathrm{vol}}+\frac{\mu}{2 \gamma}\left[\exp \gamma\left(\bar{I}_{1}-3\right)-1\right]
$$

\section{Results}

\subsection{Biaxial test response}

Figs. 6 shows the mean EPS vs. stretch curves obtained in the biaxial mechanical tests for the different load ratios. All curves started with an initial low stiffness region, which then changed into a high stiffness region. The NM mesh showed an isotropic behavior (see Fig. 6 (a)), with similar response in both axis. On the contrary, the other three meshes presented anisotropic behavior with tensile mechanical behavior along $\mathrm{B}$ direction stiffer than the A direction. In 
this group, NP and SUR showed a slight level of anisotropy (Fig. 6 (b) and (d) respectively) while SS presented a higher level (Fig. 6 (c)). Attending to the mechanical strength, SUR mesh revealed as the stiffest behavior of the four meshes and SS as the most compliant.

The SEF used to model the mechanical behavior of the meshes was defined in Eq. 1, whose characteristic parameters obtained by fitting procedure are shown in Table 3. The fitting data corresponding to the SUR mesh was obtained from prior works developed by Cordero et al. (2015), who employed a Demiray's SEF to model the isotropic contribution and Holzapfel for the anisotropic. The value of the fitting parameters is also included in the Table 3. In all cases, coefficient of determination $R^{2}$ (see Eq. 3) took values above or close to 0.9, which confirms the goodness of the fit.

Fig. 7 provides the results of the fitting process for the equibiaxial case. In the figure, curves constructed using the experimental biaxial test data (dash-dot line) and the results of the simulation (solid line) are compared. The closeness between numerical and empirical results confirms the good fit of the parameters.

\subsection{In vivo mechanical response}

Similarly to the results found in Simón-Allué et al. (2015), abdominal surface changed from a cylinder to a dome shape during the tests, as can be seen in Fig. 8. During the pneumoperitoneum, none of the sutured animals exhibited any sign of opening or breakage in the wound despite the pressure increase. Furthermore, no visible differences were found between healthy and operated specimen during the development of the test.

Inflation tests showed a maximum displacement of $44.011 \mathrm{~mm}$ in healthy animals, and 44.911 $\mathrm{mm}$ and $42.697 \mathrm{~mm}$ in specimen repaired with Neomesh Soft ${ }^{\circledR}$ and Neopore ${ }^{\circledR}$ meshes respectively. Maximum displacements were found in the central zone of the abdomen for all cases while minimum displacement values corresponded to the area between the front legs, probably given by the rigid effect of the rig cage and the breastbone. During the pneumoperitoneum test, abdomen deformed symmetrically about the longitudinal axis (craneo caudal direction) but unsymmetrically in the perpendicular axis. With respect to the this axis, a greater displacement was observed in points of the lower abdomen, towards the rear legs, rather than points of upper abdomen.

No clear alteration resulting from the mesh presence was noticed to the human eye at the end of the pneumoperitoneum, except for one specimen which presented a case of emphysema. In this case, corresponding to a specimen operated with the Neomesh Soft ${ }^{\circledR}$, the inner gas went through the abdominal cavity to the subcutaneous tissue. This provoked an excessive elongation of the skin surrounding (visible in Fig. 9) which led in an extra displacement of the dots situated on this area. This displacement was false though, since it came from the skin elongation instead of the muscle strain. Due to this, the four points altered by the emphysema were removed from the analysis. 
Five main points were studied and compared in depth, corresponding to the central, sides, upper and lower zones of the abdominal surface (see Fig. 10 (a)). Pressure-displacement curves for these points with mean and standard deviation of the four tests performed are shown in Fig. 10 (b) for healthy specimen and Fig. 10 (c) and (d) for the NM and NP mesh respectively. In these figures, horizontal axis refers to the inner pressure reached in the abdominal cavity and vertical axis plots the displacement of each point, calculated from the coordinates transformation in the three principal axis. According to these curves, dispersion was higher between the second and the sixth level of pressure, when maximum gradient of deformation was found. No great differences were found in the pressure-displacement curves between healthy and repaired specimen although slight discrepancies should be mentioned. It was noticed that NM started the big gradient of deformation right before the healthy group and the repaired with NP. Furthermore, the central point (pt. 2) of the NP showed a greater difference in displacement with respect the following point (pt. 3), difference which was not found in the healthy or NM group.

Stretching values were analysed in six segments (named A, B, C, D, E and F) of both principal directions, longitudinal (parallel to the craneo caudal) and and transversal (perpendicular to the craneo caudal). In longitudinal direction, segments were named in order from the head to the tail; in transversal direction, from the right to the left side. According to this nomenclature, stretching values for the last level of pressure were calculated for the three groups (see Fig. 11). Exact values at $12 \mathrm{mmHg}$ are gathered in Table 4. According to this bar diagram, the insertion of the NP mesh contributed to increase the elongation in the central area of the abdomen for the transversal direction, precisely where the most compliant direction of the mesh was aligned. On the contrary, no alteration was noticed in the longitudinal direction. With regard to the $\mathrm{NM}$ mesh, it was noteworthy that NM mesh provoked a shortening of the segments $\mathrm{B}$ and $\mathrm{C}$ in the longitudinal direction.

\subsection{Numerical results}

On the reconstructed FE model, results for the healthy and repaired cases were compared in terms of maximal displacements (MD), maximal principal stresses (MPS) and lagrangian strain (LS). Results were also graphically presented along the two preferential directions of the abdomen: longitudinal and transversal.

Maximal displacements (MD) along the abdominal surfaces are shown in Fig. 13 (left). As expected, maximum values were found in the central zone of the abdomen for all cases, corresponding to the mesh implantation area. MD for the healthy abdominal wall was about 37.21 $\mathrm{mm}$ at the frontal zone of the abdomen when $I A P=12 \mathrm{mmHg}$. NM and $\mathrm{NP}$ were the closest to the healthy response, reaching the maximum displacement on the mesh area with 36.07 and $36.13 \mathrm{~mm}$ respectively. No great differences were noticed between the anisotropic NP and the isotropic NM behavior concerning the MD map. With regards to the other two meshes, SS presented a MD up to $42.84 \mathrm{~mm}$, greater than any other case, while SUR showed the stiffest response with a MD of $34.41 \mathrm{~mm}$. 
Maximal principal stresses (MPS) computed on the abdominal wall model are presented in Fig. 13 (right). MPS on the healthy model were uniform distributed, presenting only small variations due to the change of material parameters assumed along the surface or in zone close to the boundary conditions. In the frontal abdomen, MPS for the healthy case reached a maximum value of $4.015 \cdot 10^{-2} \mathrm{MPa}$. When the hernial defect was computed, MPS were also modified at the frontal zone of the abdomen and turned out in higher values than those found the healthy wall. When an element in the center of the hernial defect was examined in the implant simulations, MPS took values of $0.127,0.125,0.101$ and $0.133 \mathrm{MPa}$ for the NM, NP, SS and SUR mesh respectively. Maximum values were found for the most dense implant type, which in turn revealed as the most rigid. Close to the suture zones some stress concentration was found due to the sharp change, in thickness and material, between surgical mesh and tissue. On this area, MPS on the prothesis were 0.159, 0.158, 0.107 and 0.241 MPa for the NM, NP, SS and SUR mesh respectively.

This peak of stresses caused by the surgical implant, provoked another increase of stress on the abdominal tissue surrounded. The MPS created on the soft tissue resulting from the prothesis pull were 0.087, 0.0823, 0.152 and $0.153 \mathrm{MPa}$ for NM, NP, SS and SUR mesh respectively. This peak values did not appeared on the same element but it varied depending on the stiffness shown by the mesh in each direction. For the SUR mesh, the MPS appeared on the tissue joined to the mesh sides closer to the laterals of the abdomen, while in the SS it was in the mesh sides closer to the head and tail. NM and NP shown a uniform distribution of the MPS in the tissue around the mesh.

Finally, results obtained for the healthy case and those repaired by a synthetic mesh were compared along longitudinal and transversal direction. Similarly to the prior section, longitudinal direction was defined parallel to the craneo-caudal direction and was denoted by the path A-B (see top of the Fig. 14), whereas the transversal direction lied perpendicular, denoted by the path C-D. In all cases, the abscissa shows the normalized distance of the paths A-B and C-D, where $x=0$ and $x=1$ correspond to points A/C and B/D respectively. Maximal displacements are shown in Fig. 14 (a) and (b), maximal principal stresses in (c) and (d) and logarithmic strain in (e) and (f).

According to the MD, SUR mesh restricted movement throughout of the repaired defect due to the greater stiffness. In contrast, the MD recorded throughout the SS mesh notably exceeded the displacement corresponding to the natural distensibility of a healthy abdomen. NM and NP presented the most similar response in displacements to the obtained by the healthy case but both of them slightly decreased the natural distensibility of the abdomen. Regarding the MPS, the greater stiffness of the prostheses compared to that of the animal tissue led to a marked increase in MPS in the area of the defect. This increase of MPS was specially noticeable for the NM, NP and SUR meshes, and lightly lower in the case of SS due to its great compliance. Logarithmic strain shown in the Figs. 14 (e) and (f), came influenced by the change in the material parameters, which explains the side LE peaks of both longitudinal and transversal graphics. Attending to the defect area, SUR presented a strong stiffening with respect to the healthy response, while SS mesh shown a compliance much higher than the healthy case. Again, NM and NP shown a LE quite similar to that assessed to the central area, corresponding to 
the rectus abdominis.

\section{Discussion and Conclusions}

In this work, an in silico methodology is proposed to provide surgeons with information about the immediate post-surgical performance of some hernia implants

In this work, an in silico methodology is proposed to help surgeons on the patient-specific hernia treatment, evaluating by computational simulations the surgical mesh performance on a particular abdominal cavity right after surgical procedure. To that end, several steps have been conducted. Initially, the mechanical response of four synthetic meshes have been determined and subsequently compared to the mechanical behavior of a healthy abdominal wall. In a first stage, isolated meshes were subjected to biaxial loading tests and then they were characterized based on the biaxial results. Concurrently, two of these meshes were implanted in an animal model to repair a total defect and then subjected to In vivo pneumoperitoneum tests. Finally, a patient-specific FE model of a repaired specimen was reconstructed to reproduce and validate the experimental performance.

The mechanical biaxial tests performed on the surgical meshes confirmed the anisotropy supposed on each mesh, showing a higher level of anisotropy in the case of SS, followed by the NP, SUR and finally the NM, which behaved as an isotropic material. Biaxial tests revealed SUR mesh as the stiffest one, which agreed with prior works that remarked the stiff behavior of this implant (Hernández-Gascón et al., 2011; Röhrnbauer and Mazza, 2013), and SS as the most compliant mesh used here. NP and NM remained between the other two, stiffer than SS and more compliant than SUR. Unfortunately, to the author's knowledge there is not any existing work in literature where the material properties of DIMA meshes were analysed, so results here obtained cannot be compared.

SUR material parameters, obtained from work developed by Cordero et al. (2015), agreed with the findings of Röhrnbauer and Mazza (2013) and can be correlated with Hernández-Gascón et al. (2011), although mechanical tests performed in this work were uniaxial. In vivo response of the SUR mesh was studied in Simón-Allué et al. (2015), when this mesh was inserted in a healthy abdomen and analysed following the same procedure than in this study. Results obtained in Simón-Allué et al. (2015) shown how the stiff behavior of the SUR provoked a decrease on the natural mobility of the healthy tissue in about $30 \%$. The in vivo results were properly reproduced with the numerical simulation performed in this article although lightly cushioned, since FE analysis computed a decrease in MD about 15-20\%. This difference could be explained by the fact that distinct specimen were considered. Either way, based on the strong stiffening shown in the mesh area and the peak stress values that may lead to tear the abdominal tissue, SUR mesh is not recommended for its use in hernia pathologies.

When in vivo response of the DIMA meshes was analysed, both meshes NP and NM exhibited a 
mechanical response in the abdomen close to the healthy specimen, which indicates the goodness of these implants from the mechanical approach. The anisotropy of the NP can be noticed in the increase of transversal stretching in the area where the mesh was inserted. However, this anisotropy was not visible in the longitudinal direction where NM was stiffer than the NP, contrary to the expected from biaxial tests. This difference can be explained by the fact that according to the biaxial tests, the longitudinal direction of the NP mesh behaves more similar to the NM than the transversal direction, which presents a more compliant behavior (see Fig. $7)$.

With regard to the numerical simulations performed on the FE model, results agreed to those obtained during the in vivo tests. NP and NM were the closest to the healthy response (see Fig. 13) and MD computed in numerical simulations were similar to the MD obtained after the pneumoperitoneum. The anisotropy of the NP is not visible in the displacement maps, but it can be seen in Fig. 14 (e) and (f) where the strain computed for the NP was lightly greater than the NM, concurring with the stretching analysis performed on the in vivo specimen (see Fig. 11). Based on the stretching measured along the longitudinal and transversal direction, NP seems to better reproduce the healthy results. This assumption is endorsed by the pressure displacement curves shown in Fig. 10, where NP also exhibited a mechanical behavior along the test closer to the healthy group.

Regarding the computed response of the macroporus ultralight-weight SS mesh, this implant permitted greater displacements to those needed to mimic the natural distensibility of the abdomen. Despite the benefits associated to a light-weight (LW) or (ultralight-weight) ULW mesh in terms of foreign body reaction, infection risk or postoperative pain (Klosterhalfen et al., 2002; Brown and Finch, 2010; Li et al., 2012), this type of meshes are also frequently related to a higher risk of breakage (Lintin and Kingsnorth, 2014; Blázquez Hernando et al., 2015). Although additional mechanical tests should be performed to address breaking stretch and stress and properly determine the risk of breakage, based on the excessive elongation observed in this mesh the use of SS is not recommended for hernia repair.

This study is not exempt from some limitations. First, experimental data for the mechanical characterization of meshes was obtained by a fitting procedure of biaxial tests. Further information from other mechanical tests, such as inflation or bulge test, would be useful to complete the characterization. The in vivo study limitations were already mentioned in Simón-Allué et al. (2015). Moreover, widen the in vivo experimentation to the use of the other meshes involved in the study, as the SS, would help to complete the results. During the pneumoperitoneum tests, only the passive response at low pressure is studied. However, it would be necessary to analyse the response of the abdomen when inner pressure is increased, as a result of physiological actions such as sneeze or standing cough. This may imply to spread the analysis to the active response of the muscle. Attending to the FE model and numerical simulation, 3D model was based on the measurements taken by cameras during the experimental tests. This method should be improved in order to increase the accuracy of the reconstruction, specially in the zones were the boundary conditions were assessed. The use of solid elements to simulate the surgical mesh may introduce some bending stiffness that does not exist on the real meshes. Instead, the use of membrane elements should be recommended in 
further studies. Additionally, material parameters assumed for the healthy abdominal tissue were extrapolated from the distribution obtained after the inverse analysis. However, those distributions were obtained for a specific specimen and they may vary when a different specimen is considered. Lastly, this study makes reference to the short term response of the mesh after insertion. Long term study, complemented to a biological analysis of the interaction mesh-tissue would definitely improve significance of this findings.

Despite this limitations, a novel methodology was presented here able to provide relevant and useful information about the suitability of surgical meshes. Based on biaxial data of four surgical meshes, their effect after being used to correct a total defect performed on a healthy abdominal was analysed. Results were given in terms of maximal displacements, stresses and strains provoked on the abdomen. By using this methodology on a clinical environment, mechanical data about the in vivo performance of different prosthesis can be obtained prior to the surgical procedure. This information may be used to select the most suitable mesh with regard to the particular patient, whose mechanical properties would be obtained during the surgical procedure. Although the numerical model needs to be improved before providing totally reliable mechanical information, current methodology contributes to compare post inmediative response of different meshes and allows to identify potential disadvantages. As a result and once this methodology was automatized, it may contribute to help surgeons to choose which mesh better reproduce the mechanical response of the healthy tissue, and thereby reducing the risk of mesh breakage, pain or discomfort in the patient.

\section{Acknowledgements}

Research was supported by grants from the Spanish Ministry of Economy and Competitiveness (DPI2014-54981-R, DPI2017-84047-R). The work was performed by the ICTS "NANBIOSIS" specifically by the Tissue \& Scaffold Characterization Unit (U13), of the CIBER in Bioengineering, Biomaterials \& Nanomedicne (CIBER-BBN at the University of Zaragoza). We also thank the Spanish Ministry of Economy and Competitiveness for the financial support to R. SimónAllué through the grant BES-2012-053422 and A. Ortillés through the grant FPU13/03782.

\section{References}

Amid, P., Shulman, A., and Lichtenstein, I. (1995). The lichtenstein open "tension-free" mesh repair of inguinal hernias. Surgery today, 7(25):619-625.

Blázquez Hernando, L., García Ureña, M., López Monclús, J., Lersundi Robin del Valle, A., Melero Montes, D., Cruz Cidoncha, A., Jiménez Ceinos, C., and Castelló Pavó, C. (2015). Roturas de malla: una causa poco frecuente de recidiva herniaria. Revista Hispanoamericana de Hernia, 3(4):155-159. 
Brown, C. N. and Finch, J. G. (2010). Which mesh for hernia repair? Annals of the Royal College of Surgeons of England, 92(4):272-278.

Conze, J. and Klinge, U. (1999). Biocompatibility of biomaterials-clinical and mechanical aspects. In Schumpelick, V. and Kingsnorth, A. N., editors, Incisional Hernia, chapter 14, pages 169-177. Springer Berlin Heidelberg, Berlin, Heidelberg.

Cordero, A., Hernández-Gascón, B., Pascual, G., Bellón, J. M., Calvo, B., and Peña, E. (2015). Biaxial Mechanical Evaluation of Absorbable and Nonabsorbable Synthetic Surgical Meshes Used for Hernia Repair: Physiological Loads Modify Anisotropy Response. Annals of Biomedical Engineering.

Deerenberg, E., Verhelst, J., Hovius, S., and Lange, J. (2016). Mesh expansion as the cause of bulging after abdominal wall hernia repair. International Journal of Surgery Case Reports, (28):200-203.

Gasser, T. C., Ogden, R. W., and Holzapfel, G. A. (2006). Hyperelastic modelling of arterial layers with distributed collagen fibre orientations. Journal of The Royal Society Interface, $3(6): 15-35$.

Gefen, A. (2012). Patient-Specific Modeling in Tomorrow's Medicine. Springer Science \& Business Media.

Goenezen, S., Barbone, P., and Oberai, A. A. (2011). Solution of the nonlinear elasticity imaging inverse problem: The incompressible case. Computer Methods in Applied Mechanics and Engineering, 200:1406 - 1420.

Hernández, B., Peña, E., Pascual, G., Rodríguez, M., Calvo, B., Doblaré, M., and Bellón, J. (2011). Mechanical and histological characterization of the abdominal muscle. a previous step to modelling hernia surgery. Journal of the Mechanical Behavior of Biomedical Materials, 4(3):392-404.

Hernández-Gascón, B., Peña, E., Melero, H., Pascual, G., Doblaré, M., Ginebra, M., Bellón, J., and Calvo, B. (2011). Mechanical behaviour of synthetic surgical meshes: Finite element simulation of the herniated abdominal wall. Acta Biomaterialia, 7(11):3905-3913.

Holzapfel, G. A. (2000). Nonlinear Solid Mechanics. Wiley, New York.

Kauer, M., Vuskovic, V., Dual, J., Szekely, G., and Bajka, M. (2002). Inverse finite element characterization of soft tissues. Medical Image Analysis, 6(3):275-287.

Klosterhalfen, B., Junge, K., and Klinge, U. (2002). The lightweight and large porous mesh concept for hernia repair. Expert Review Medical Devices, 2(1):103-117.

Kulacoglu, H. (2011). Current options in inguinal hernia repair in adult patients. Hippokratia, $15(3): 223-231$.

Li, J., Ji, Z., and Cheng, T. (2012). Lightweight versus heavyweight in inguinal hernia repair: a meta-analysis. Hernia, 16(5):529-539.

Lichtenstein, I. and Shulman, A. (1986). The tension-free hernioplasty. International surgery, 1(71):1-4.

Lintin, L. A. D. and Kingsnorth, A. N. (2014). Mechanical failure of a lightweight polypropylene mesh. Hernia, 18(1):131-133.

Marquardt, D. (1963). An algorithm for least-squares estimation of nonlinear parameters. SIAM Journal on Applied Mathematics, 11:431-441.

Oberai, A. A., Gokhale, N. H., Goenezen, S., Barbone, P. E., and Timothy, J. (2009). Linear and nonlinear elasticity imaging of soft tissue in vivo: demonstration of feasibility. Physics in Medicine and Biology, 54(5):1191-1207. 
Paajanen, H. and Hemunen, H. (2004). Long-term pain and recurrence after repair of ventral incisional hernias by open mesh: clinical and mri study. Langenbeck's Archives of Surgery, 389:366-370.

PhotoModeler (2013). PhotoModeler Scanner. Eos Systems Inc, Vancouver, Canada.

Röhrnbauer, B. and Mazza, E. (2013). A non-biological model system to simulate the in vivo mechanical behavior of prosthetic meshes. Journal of the Mechanical Behavior of Biomedical Materials, 20:305-315.

Rutkow, I. M. (2003). Demographic and socioeconomic aspects of hernia repair in the united states in 2003. Surgical Clinics of North America, 83(5):1045 - 1051. Hernia Repair.

Sacks, M. S. (2000). Biaxial mechanical evaluation of planar biological materials. Journal of Elasticity, 61(1-3):199-246.

Sakorafas, G. H., Halikias, I., Nissotakis, C., Kotsifopoulos, N., Stavrou, A., Antonopoulos, C., and Kassaras, G. A. (2001). Open tension free repair of inguinal hernias; the Lichtenstein technique. BioMed Central Surgery, 1(1):1-3.

Schoenmaeckers, E. J., Wassenaar, E. B., Raymakers, J. T., and Rakic, S. (2010). Bulging of the Mesh After Laparoscopic Repair of Ventral and Incisional Hernias. Journal of the Society of Laparoendoscopic Surgeons, 4:541-546.

Simón-Allué, R., Calvo, B., Oberai, A., and Barbone, P. (2017). Towards the mechanical characterization of abdominal wall by inverse analysis. Journal of the mechanical behavior of biomedical materials, 66:127-137.

Simón-Allué, R., Montiel, J., Bellón, J., and Calvo, B. (2015). Developing a new methodology to characterize in vivo the passive mechanical behavior of abdominal wall on an animal model. Journal of the Mechanical Behavior of Biomedical Materials, 51:40-49.

Steel, R. and Torrie, J. (1960). Principles and procedures of statistics: with special reference to the biological sciences. McGraw-Hill.

Veronda, D. and Westmann, R. (1970). Mechanical characterization of skin - finite deformations. Journal of Biomechanics, 3(IN9):111-122. 


\begin{tabular}{lcc}
\hline Commercial Name & Type & Density \\
\hline Neomesh Soft ${ }^{\circledR}(\mathrm{NM})$ & Light-weight & $40 \mathrm{~g} / \mathrm{m}^{2}$ (LW) \\
Neopore $^{\circledR}(\mathrm{NP})$ & Ultra light-weight & $32 \mathrm{~g} / \mathrm{m}^{2}$ (ULW) \\
Neomesh SuperSoft $^{\circledR}(\mathrm{SS})$ & Ultra light-weight & $18.10 \mathrm{~g} / \mathrm{m}^{2}(\mathrm{ULW})$ \\
Surgipro $^{T M}$ (SUR) & Heavy-weight & $84 \mathrm{~g} / \mathrm{m}^{2}$ (HW) \\
\hline
\end{tabular}

Table 1

Description of the four surgical meshes tested in this study. 
Test name

A axis

B axis

A axis

$\mathrm{B}$ axis

TA:TB

displacement

\begin{tabular}{ccccc}
\hline $1: 1$ & $3.0(4.0)$ & $3.0(4.0)$ & $0.3(0.4)$ & $0.3(0.4)$ \\
\hline $1: 0.5$ & $3.0(4.0)$ & $1.5(2.0)$ & $0.3(0.4)$ & $0.15(0.2)$ \\
\hline $1: 0.75$ & $3.0(4.0)$ & $2.25(3.0)$ & $0.3(0.4)$ & $0.225(0.3)$ \\
\hline $0.5: 1$ & $1.5(2.0)$ & $3.0(4.0)$ & $0.15(0.2)$ & $0.3(0.4)$ \\
\hline $0.75: 1$ & $2.25(3.0)$ & $3.0(4.0)$ & $0.225(0.3)$ & $0.3(0.4)$ \\
\hline
\end{tabular}

Table 2

Loading protocols biaxial tests for the DIMA meshes. Plain values correspond to Neomesh Soft ${ }^{\circledR}$ and Neopore ${ }^{\circledR}$; values in brackets, to the Neomesh Supersoft ${ }^{\circledR}$. 


\begin{tabular}{lcccccc}
\hline Mesh & $D_{1}[\mathrm{MPa}]$ & $D_{2}[-]$ & $k_{1}[\mathrm{MPa}]$ & $k_{2}[-]$ & $\rho[-]$ & $R^{2}$ \\
\hline $\mathrm{NM}$ & - & - & 14.92 & 40.1 & 0 & 0.973 \\
$\mathrm{NP}$ & - & - & 11.28 & 51.4 & 0.02 & 0.919 \\
$\mathrm{SS}$ & - & - & 0.153 & 40.5 & 0.25 & 0.917 \\
SUR $^{*}$ & 1.73 & 11.7 & $3.51 \cdot 10^{-2}$ & 88.8 & 1 & - \\
\hline
\end{tabular}

Table 3

Material parameters for the NM, NP and SS meshes generated by the fitting procedure. All meshes were modelized through the SEF defined in Eq. 1, except for SUR mesh, where a combination between Demiray's and Holzapfel's SEF was employed. $D_{1}$ and $D_{2}$ correspond to material parameters Demiray's SEF. 


\begin{tabular}{lcccccc}
\hline CS & A & B & C & D & E & F \\
\hline Healthy & 15.45 & 7.56 & 5.90 & 3.68 & 6.49 & 15.36 \\
Neomesh & 24.14 & 2.72 & 6.78 & 6.80 & 12.85 & 13.30 \\
Neopore & 27.79 & 26.30 & 14.24 & 11.25 & 18.71 & 15.17 \\
\hline \hline LC & $\mathbf{A}$ & $\mathbf{B}$ & $\mathbf{C}$ & $\mathbf{D}$ & $\mathbf{E}$ & $\mathbf{F}$ \\
\hline Healthy & 2.46 & 0.80 & 0.30 & 1.94 & 3.12 & 5.06 \\
Neomesh & 2.79 & -1.16 & -1.88 & 0.35 & 5.17 & 6.33 \\
Neopore & 2.12 & 1.49 & 0.07 & 2.31 & 2.74 & 4.60 \\
\hline \hline
\end{tabular}

Table 4

Mean stretching values for $12 \mathrm{mmHg}$ in the transverse (also cross-section, CS) and longitudinal (LS) direction (values in \%). Segments defined in Fig. 12. 
Material and Methods outline followed on

Material and Methods
this paper distribution:

on animal model.

- Mesh insertion

- Pneumoperitoneum

tests

- 3D measurements

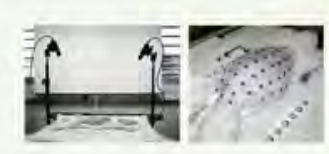

In vivo

testing

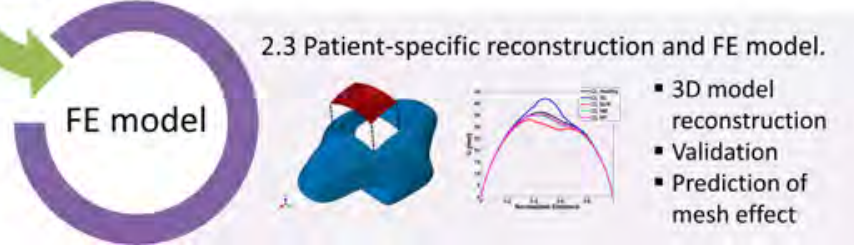

Fig. 1. Overview of present work, with the numbering employed in the section Material and methods. 


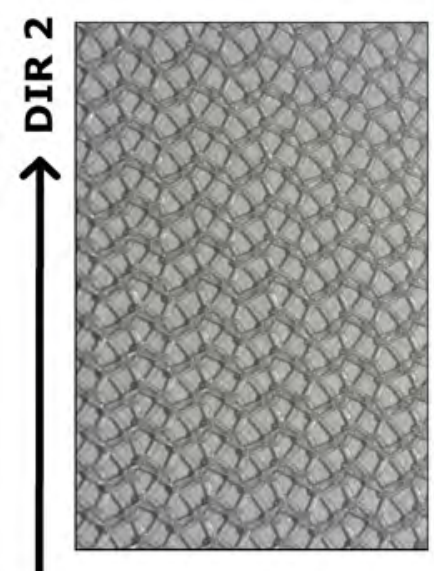

(a) Neomesh Soft ${ }^{\circledR}$

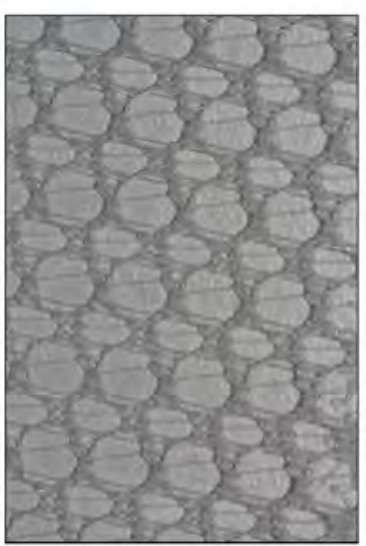

(b) Neopore ${ }^{\circledR}$

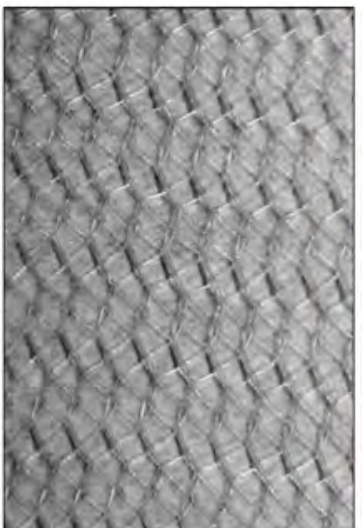

(c) Neomesh Supersoft ${ }^{\circledR}$

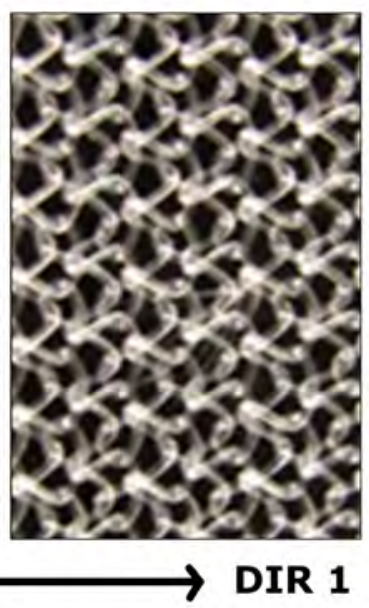

(d) Surgipro ${ }^{\mathrm{TM}}$

Fig. 2. Details of the four synthetic meshes and test directions. 


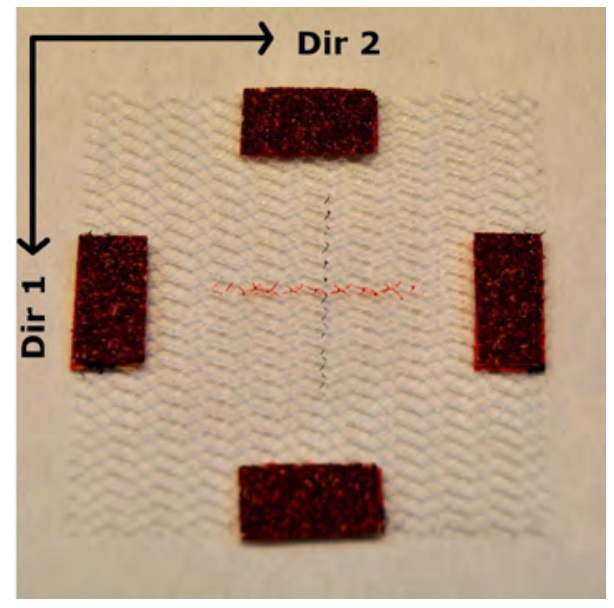

(a) Directions on the mesh.

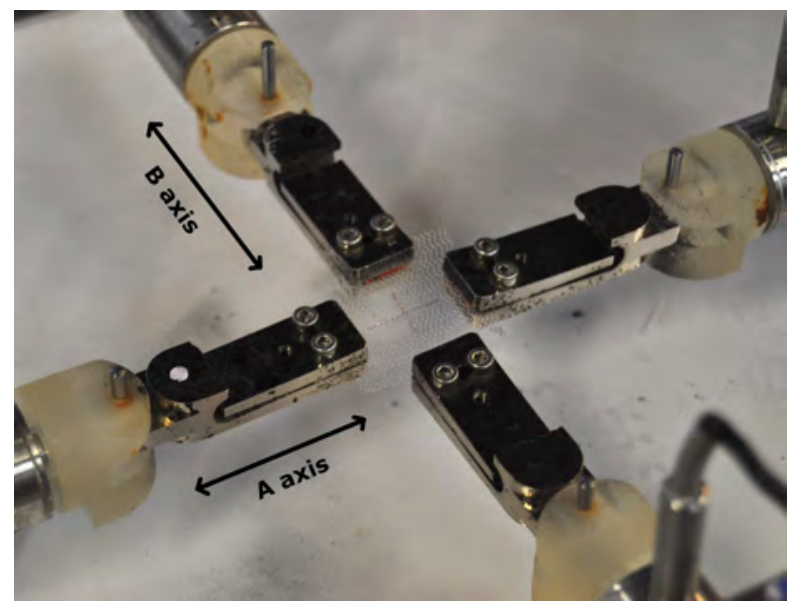

(b) Mesh setup.

Fig. 3. Biaxial setup. 


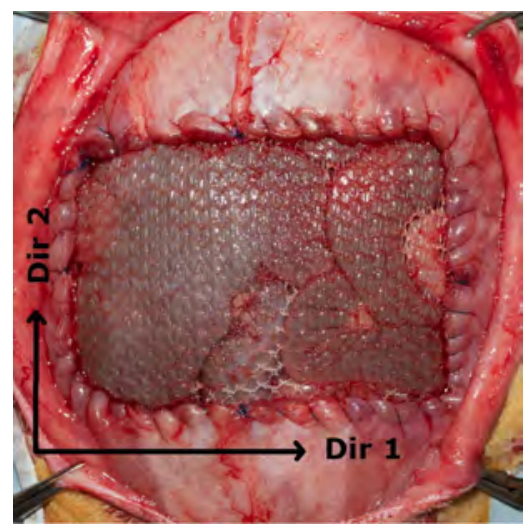

(a)

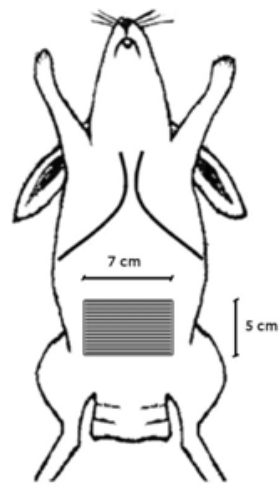

(b)

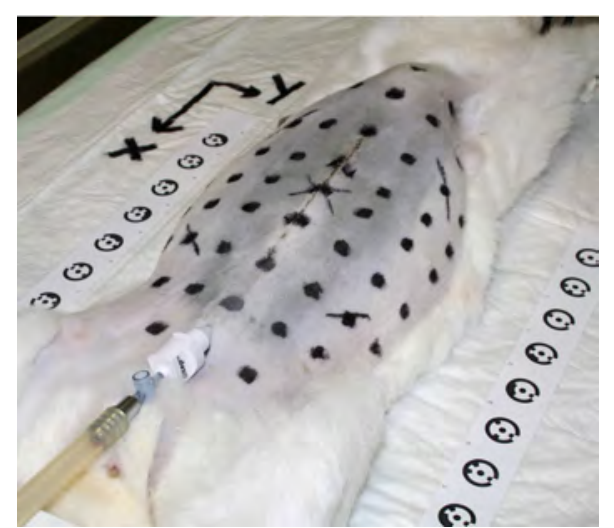

(c)

Fig. 4. Details of the implanted mesh in in the rabbit: (a) Neopore ${ }^{\circledR}$ mesh at the moment of mesh implantation. (b) Mesh location in the abdomen. (c) External aspect of the abdomen after wound closure. 
Mechanical properties of each surgical mesh depicted in Section 3.1
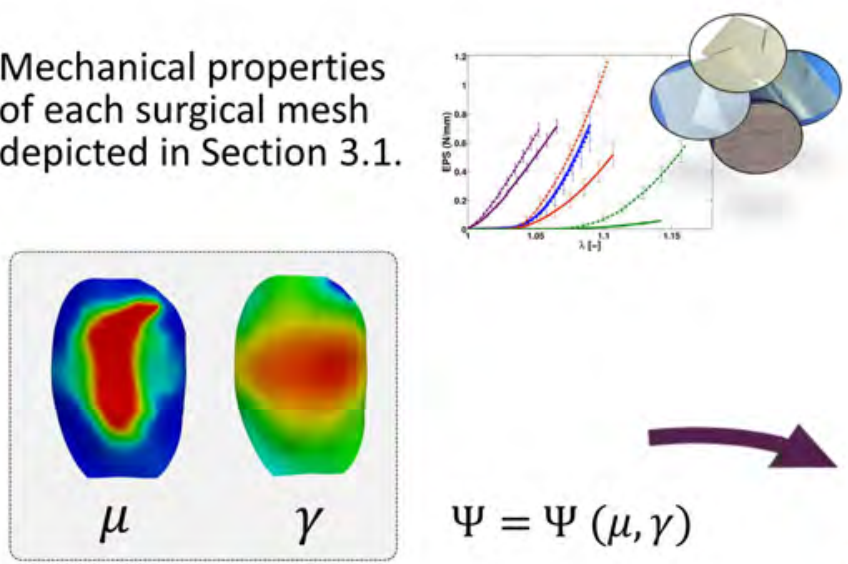

Mechanical parameter distribution along the anterolateral abdominal wall *[Simón-Allué et al. 2017]

Fig. 5. FE model reconstructed from the in vivo testing with NM inserted. 


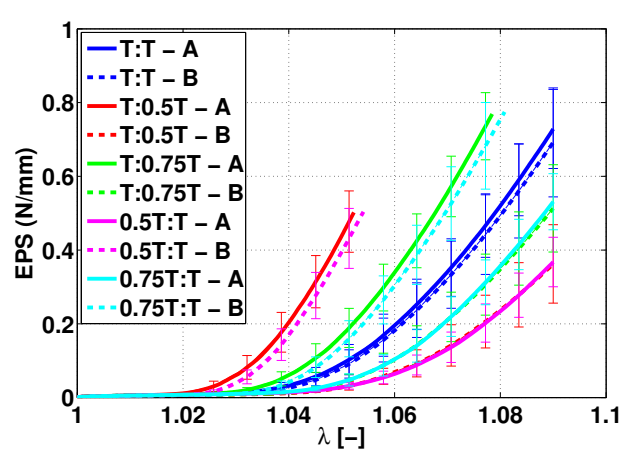

(a) Neomesh Soft ${ }^{\circledR}$ mesh

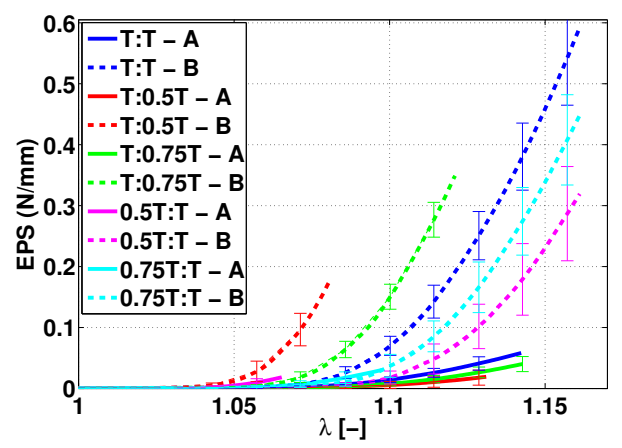

(c) Neomesh Supersoft ${ }^{\circledR}$ mesh

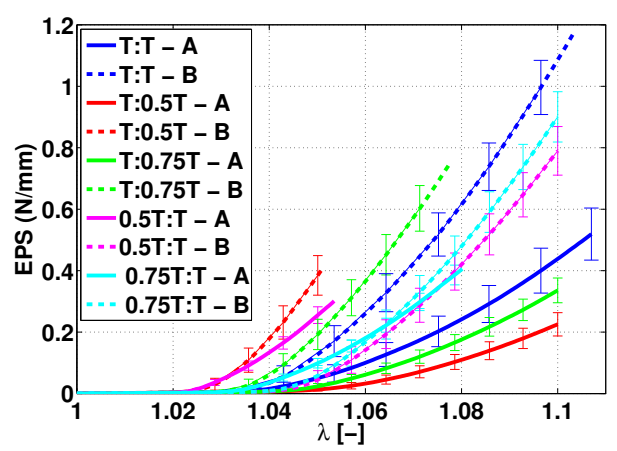

(b) Neopore ${ }^{\circledR}$ mesh

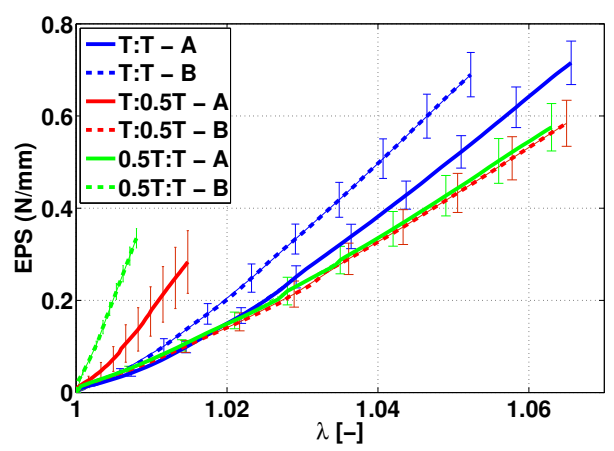

(d) Surgipro ${ }^{T M} *$

Fig. 6. Experimental data obtained in the biaxial tests for the four synthetic meshes. (*SUR data obtained from (Cordero et al., 2015)) 


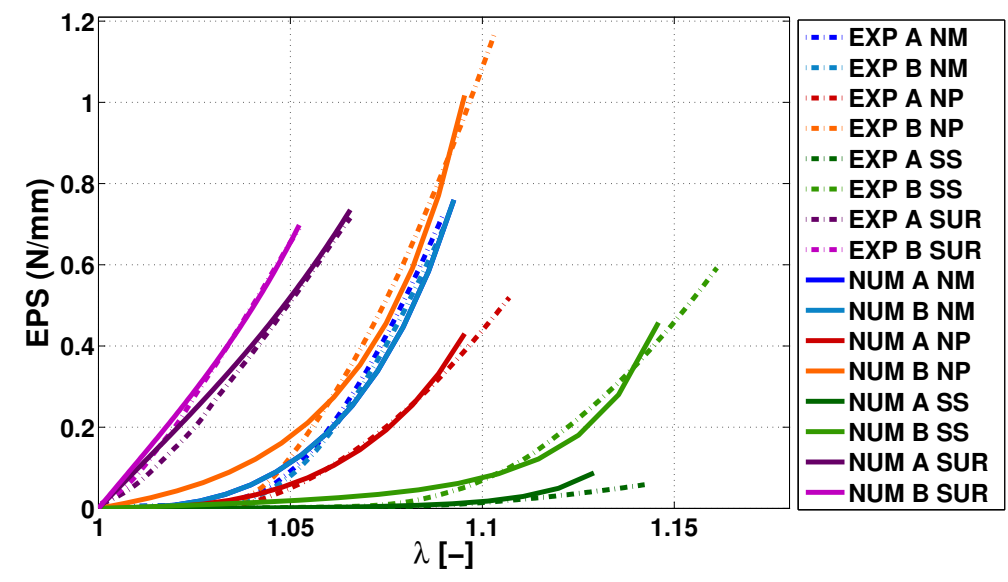

Fig. 7. Numerical fitting of the biaxial tests for the four meshes. 


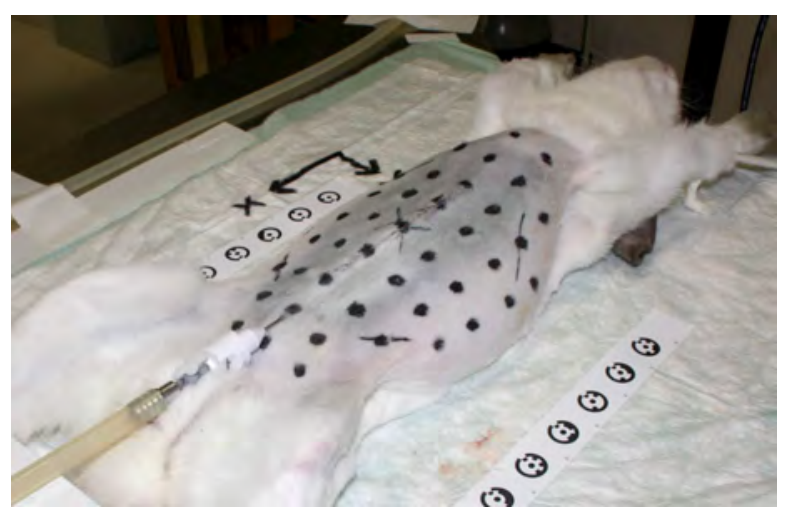

(a) $P=0 \mathrm{mmHg}$

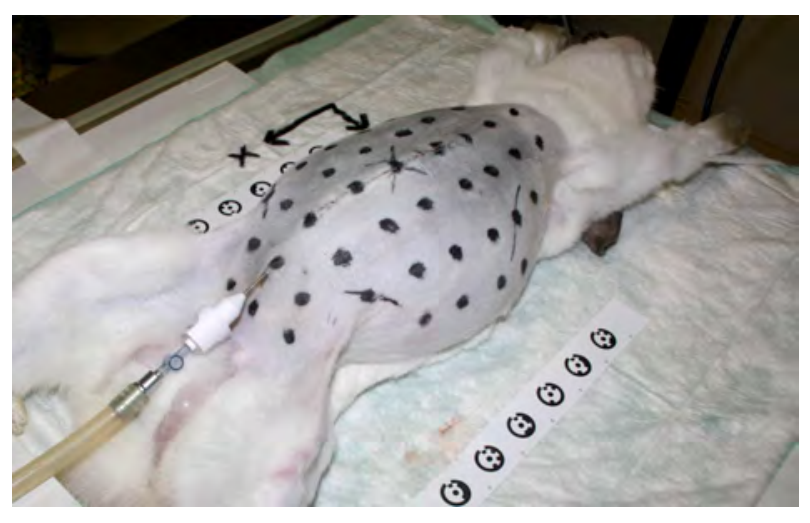

(b) $P=12 \mathrm{mmHg}$

Fig. 8. Specimen with the mesh inserted in the initial (a) and final (b) instant of the inflation test. 


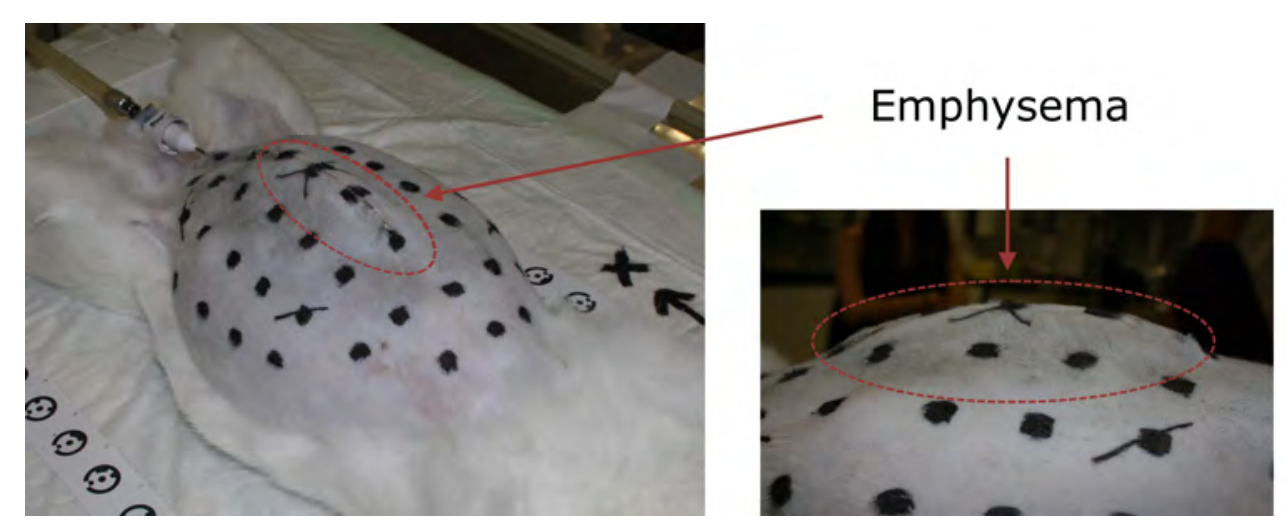

Fig. 9. Emphysema resulting from the test in one of the specimen. 


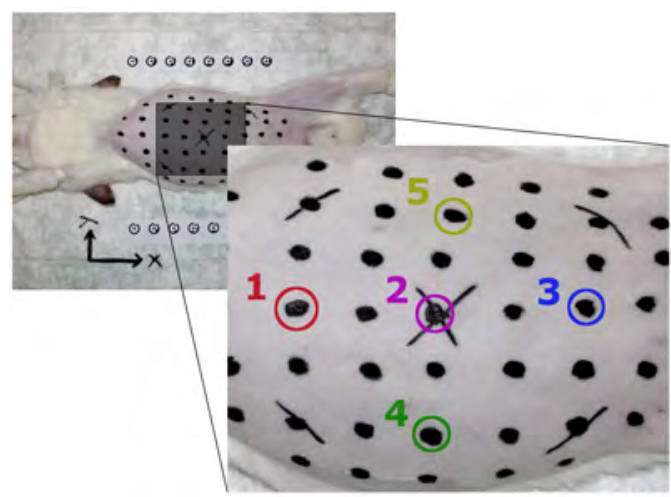

(a) Reference points.

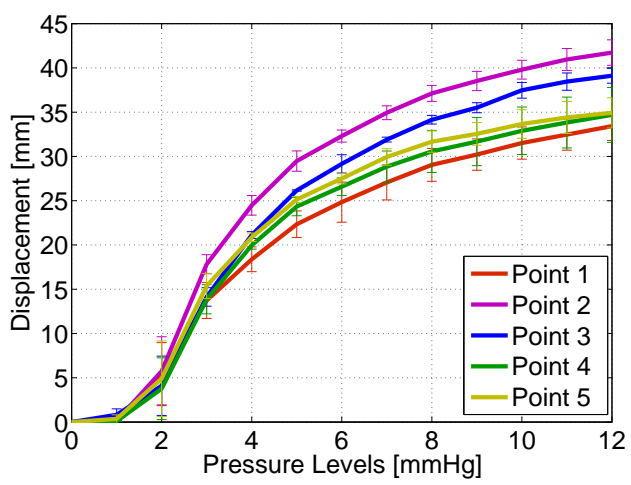

(c) Neomesh Soft. ${ }^{\circledR}$

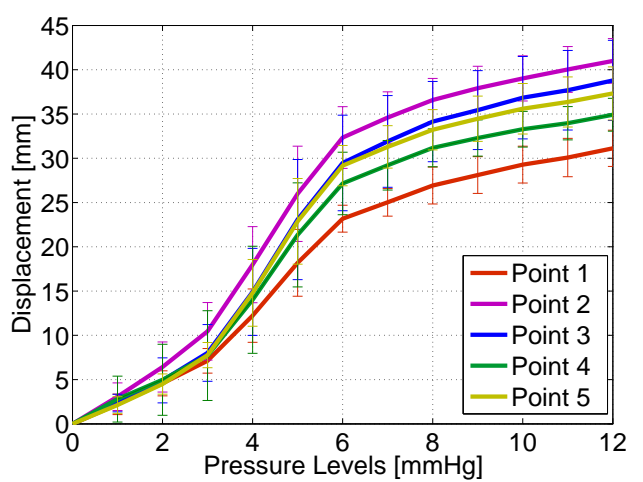

(b) Healthy.

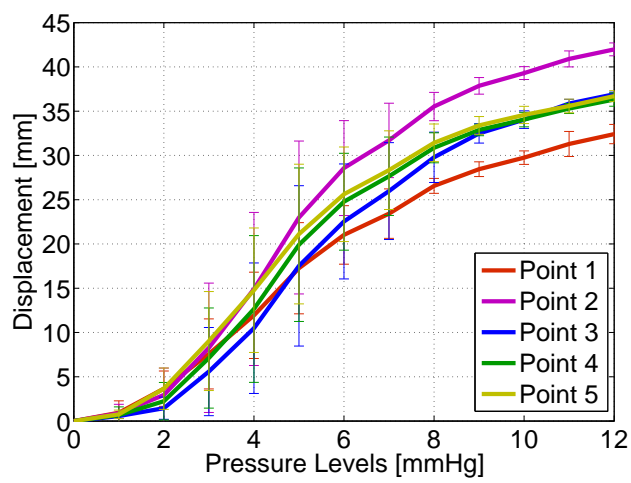

(d) Neopore. ${ }^{\circledR}$

Fig. 10. Pressure-displacement curves for main five points of the abdominal surface for the healthy and repaired specimen. Mean and standard deviation are shown. 


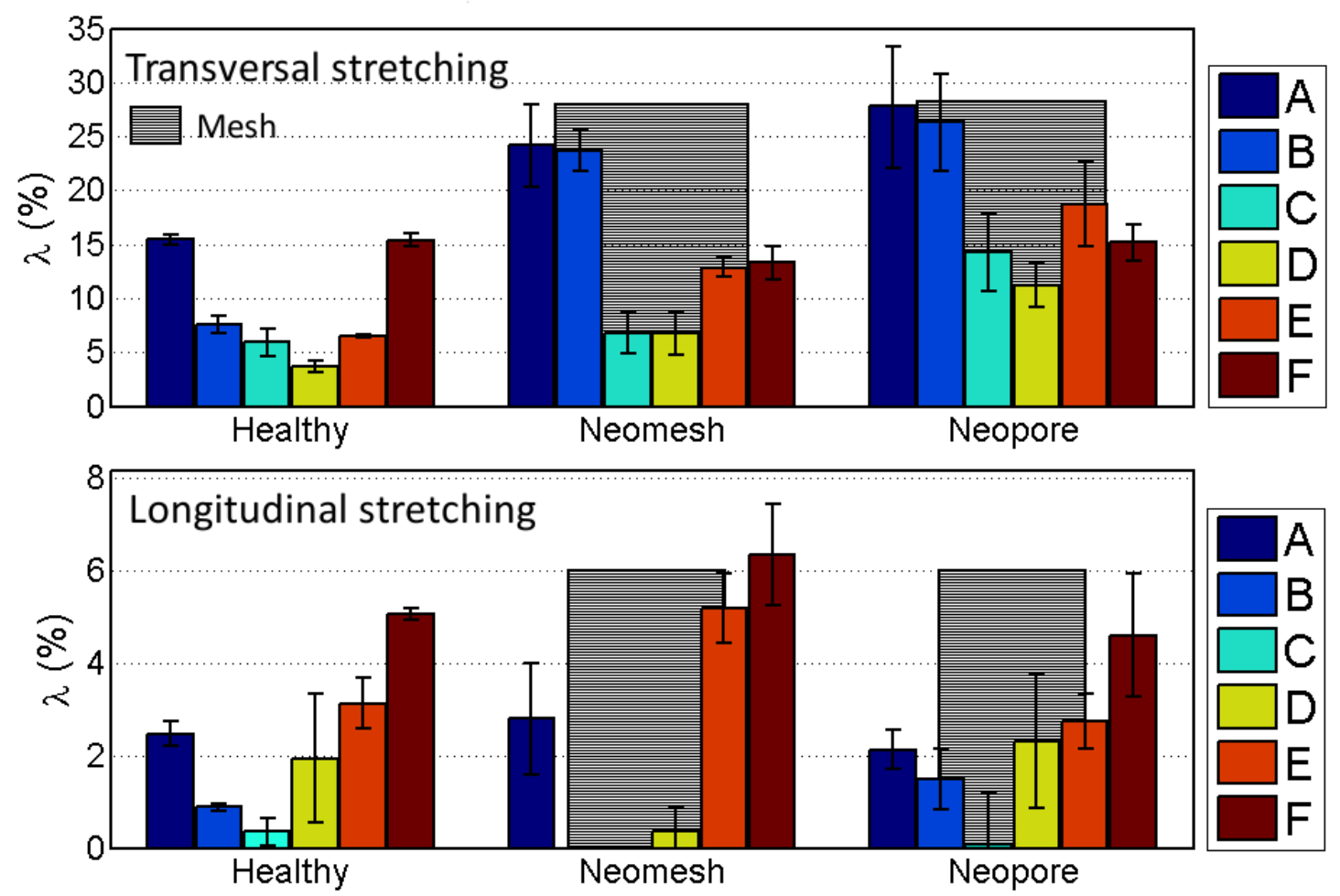

Fig. 11. Mean and standard deviation of stretching values according to the segments delimited in Fig. 12. Exact values are gathered in Table 4. 


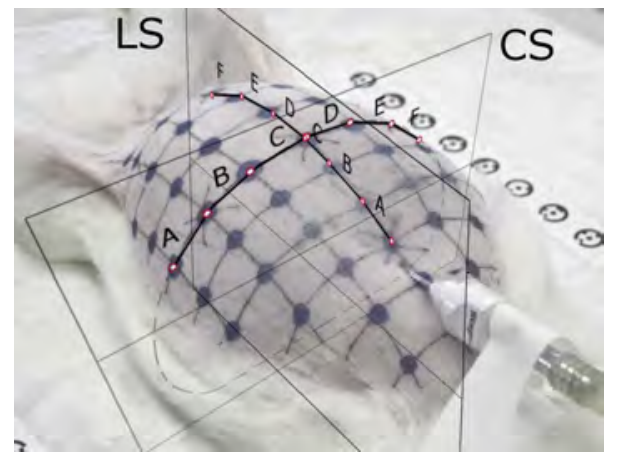

Fig. 12. Segments defined on the abdominal surface. 


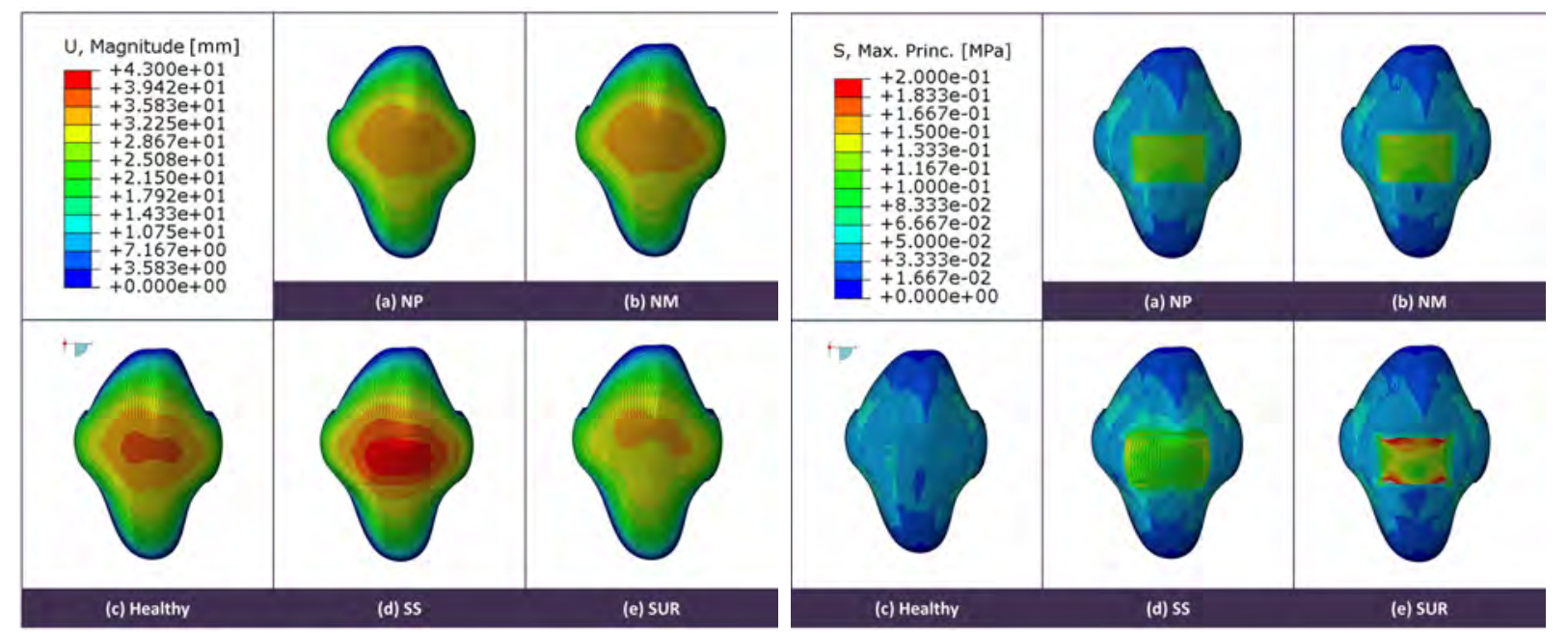

Fig. 13. Displacement $[\mathrm{mm}]$ and Maximal principal stresses $[\mathrm{MPa}]$ computed on the same model at the end of the test $(I A P=12 \mathrm{mmHg})$ for the healthy and four meshes considered in the study. 


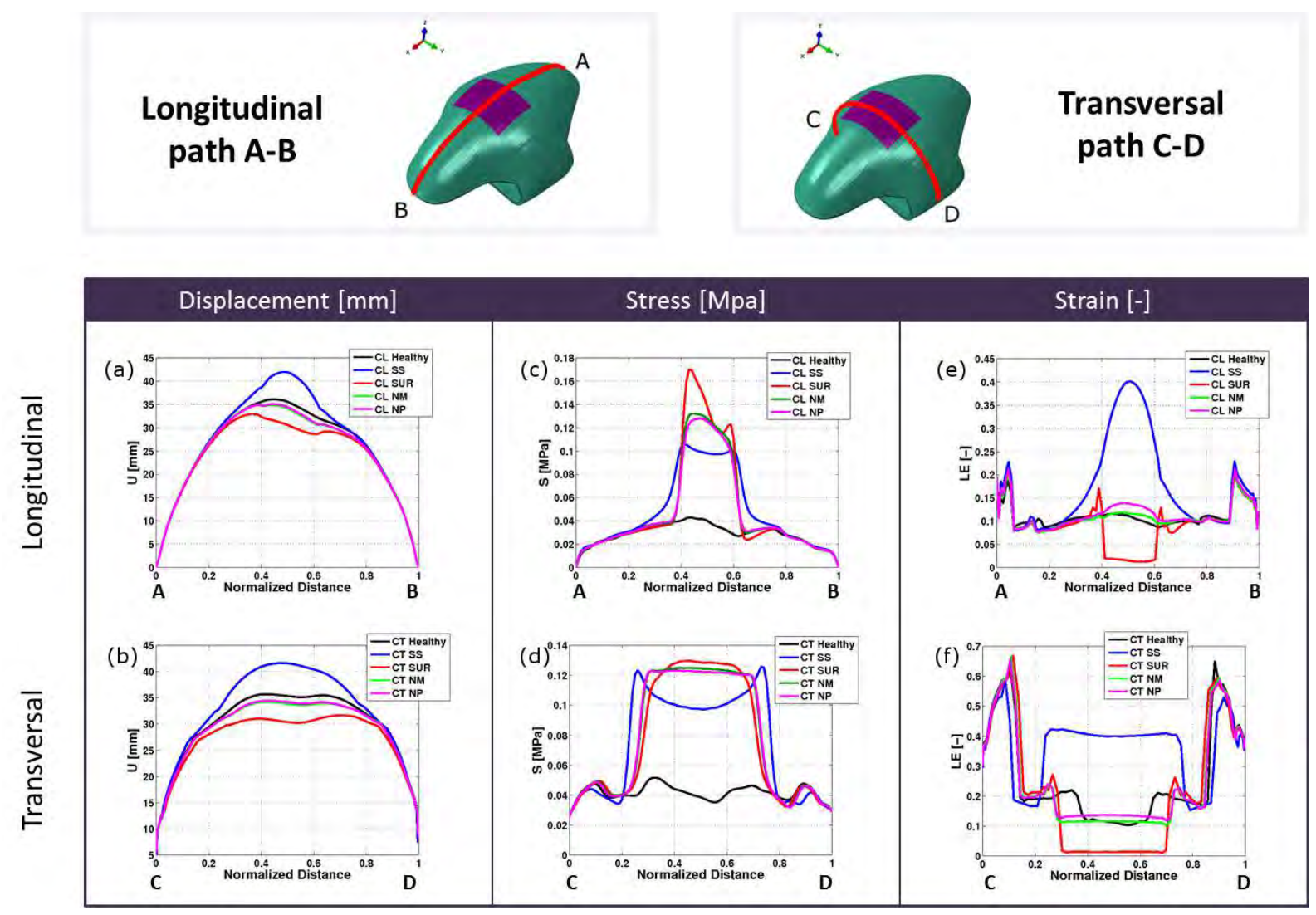

Fig. 14. Displacements (a,b), maximal stresses (c,d) and logarithmic strain (e,f) computed along the longitudinal (A-B) and the transversal (C-D) paths the healthy specimen and those repaired with four surgical meshes. 